17 Pasamanick B, Scarpitti FR, Lefton $M$, Wernert JJ, McPheeters H. Home vs hospital care for schizophrenics. $\mathcal{F} A M A 1964 ; 187: 177-81$.

18 Gaind R, Barnes TRE. Depot clinics. In: Praag HM van, Lader MH, Rafaelson OJ, Sacher EJ, eds. Handbook of biological psychiatry, part VI. Practical applications of psychotropic drugs and other biological treatments. New York: Dekker, 1981:149-79.

19 Anonymous. Long acting phenothiazines in schizophrenia [Editorial]. $\mathrm{Br} \mathrm{Med}$ f 1971;i:189-90.

20 Renton CA, Affleck JW, Carstairs M, Forrest AD. A follow up of schizophrenic patients in Edinburgh. Acta Psychiatr Scand 1963;39:548-600.

21 Leff JP, Wing TK. Trial of maintenance therapy in schizophrenia. $\mathrm{Br} \mathrm{Med} \mathcal{F}$ 1971;iii:599-604.

22 Johnson DAW. The expectation of outcome for maintenance therapy in chronic schizophrenics. Br f Psychiatry 1976;128:246-50.

23 Falloon I, Watt DC, Shepherd M. A comparative controlled trial of pimozide and fluphenazine decanoate in the continuation therapy of schizophrenia. and fluphenazine decanoate in

24 Barnes TRE, Milavich G, Curson DA, Platt SD. The use of the social behaviour assessment schedule (SBAS) in a trial of maintenance anti- psychotic therapy in schizophrenic outpatients: pimozide versus fluphenazine. Soc Psychiatry 1983;18:193-9.

25 Hirsch SR, Gaind R, Rohde OD, Stevens BC, Wing JK. Outpatien maintenance of chronic schizophrenic patients with long-acting fluphenazine: double blind placebo trial. Br Med F 1973;i:633-7.

26 Curson DA, Barnes TRE, Bamber RW, Platt SD, Hirsch SR, Duffy JC. Long term depot maintenance of chronic schizophrenic outpatients. The seven year follow up of the Medical Research Council fluphenazine/placebo trial. II. The incidence of compliance problems, side effects, neurotic symptoms, and depression. Br f Psychiatry 1985;146:469-74.

27 Crumpton $\mathrm{N}$. The role of drugs in maintaining patients in the community. In: David GR, Freeman HL, eds. Treatment of mental disorders in the community. London: Baillière, Tindall and Cassell, 1968:15-24.

28 Griffiths R. Community care: agenda for action. London: HMSO, 1988.

29 Wing JK, Furlong R. A haven for the severely disabled within the context of a comprehensive psychiatric community service. Br f Psychiatry 1986;149: $449-57$.

(Accepted 9 fune 1988)

\title{
Transabdominal chorionic villus biopsy in second and third trimesters of pregnancy to determine fetal karyotype
}

\author{
L Pijpers, M G J Jahoda, A Reuss, J W Wladimiroff, E S Sachs
}

\begin{abstract}
Transabdominal chorionic villus biopsy is an established method of obtaining material for analysing fetal chromosomes in the first trimester of pregnancy but has not been widely used for karyotyping in the second and third trimesters, when rapid results are required. The technique was evaluated in two groups of patients, comprising 106 at risk of having a fetus with chromosomal anomalies (105) or $\mathrm{X}$ linked disease (one) studied between 13 and 22 weeks (median 15 weeks) of gestation (group 1) and 21 with abnormal fetal findings on ultrasonography studied between 13 and 38 weeks (median 27 weeks) (group 2). Chorionic tissue was collected at the first attempt in 109 patients and at the second attempt in a further 17 independent of the position of the placenta. In one case from group 1 sufficient material for analysis could not be obtained. Seven abnormal karyotypes (six in group 1 and one in group 2) were diagnosed. Karyotyping was unsuccessful in two cases in group 1 (at 17 and 18 weeks' gestation) and in two in group 2 (at 29 and 38 weeks' gestation). Follow up of group 1 four weeks after sampling showed no signs of adverse fetal development apart from one unexplained intrauterine fetal death.
\end{abstract}

The findings suggest that chorionic sampling is a safe and valuable additional technique for the late detection of chromosomal defects.

\section{Introduction}

Transabdominal and transcervical sampling of chorionic villuses during the first trimester of preg-

Department of Obste University Hospital

Rotterdam-Dijkzigt, 3015

GD Rotterdam, The

Netherlands

L Pijpers, MD,

gynaecologist

M G J Jahoda, MD,

gynaecologist

JW Wladimiroff, MD,

professor

Department of Clinical

Genetics, Erasmus

University, Rotterdam,

The Netherlands

A Reuss, MD, research fellow

E S Sachs, MD, clinical

geneticist

Correspondence to:

Professor Wladimiroff.
Renal anomalies

Non-structural defect:

Fetal hydrops

Severe growth retardation
Hygroma colli nancy are highly effective and reliable techniques in detecting fetal diseases. ${ }^{12}$ Whereas sampling during the first trimester allows karyotyping to be performed within 36 hours after the procedure, karyotyping in the second and third trimesters is still mainly carried out on amniotic cells obtained by amniocentesis, with the disadvantage that the results are not available until two or three weeks later. This delay is particularly unacceptable in late pregnancy, when knowing the fetal karyotype is essential for obstetric management if certain structural defects are present in the fetus.

Preliminary reports suggest that transabdominal chorionic villus sampling may be useful for rapid fetal karyotyping in late pregnancy. ${ }^{3.5} \mathrm{We}$ present our experience with this technique for rapid karyotyping in the second and third trimesters.

\section{Patients and methods}

Between February and October 1987 we carried out transabdominal chorionic villus sampling in two groups of patients (table I). One group consisted of 105 patients who had a fetus at risk of chromosomal anomalies and one whose fetus was at risk of the $\mathrm{X}$ linked abnormality Paine's syndrome (group 1); the median gestational age was 15 weeks (range 13-22 weeks). The other group comprised 21 patients with abnormal fetal findings on ultrasonography (group 2); the median gestational age was 27 weeks (range 13-38 weeks). We explained the technique and its purpose to the patients and their partners.

The procedure started with identification of the placenta. After disinfection of the skin a 20 gauge spinal needle without a stylet (TSK Supra, West Germany) flushed with heparin was attached to a $20 \mathrm{ml}$ syringe filled with $5 \mathrm{ml}$ RPMI medium and introduced into the placenta under continuous ultrasound guidance with a linear array real time scanner (Hitachi, transducer carrier frequency $3.5 \mathrm{MHz}$ ). The transducer was close to the site of insertion and so had been disinfected with povidone-iodine spray. Sterile gloves and contact gel were used throughout the procedure. Within the placenta the tip of the needle was placed close to the chorionic membrane and slowly moved vertically and obliquely under a continuous vacuum. The chorionic tissue collected was dissected immediately by an experienced technician; at least $10 \mathrm{mg}$ of tissue was needed for karyotyping. During the procedure the needle was not inserted more than twice. When the maternal blood group was $\mathrm{Rh}$ negative we gave a single intramuscular dose of rhesus immunoglobulin $125 \mu \mathrm{g}$ directly after the procedure. 
At first we analysed the chorionic tissue directly according to the method of Simoni et al,${ }^{6}$ but later we adopted the method of Gibas et al, ${ }^{7}$ in which the villuses were incubated with 5-fluoro-2-deoxyuridine for 19 hours at $37^{\circ} \mathrm{C}$ and then with thymidine for five hours. Slides were stained with the trypsin and giemsa method. We saw the patients in group 1 again four weeks after sampling to ask about loss of blood vaginally and leakage of amniotic fluid and for ultrasonography to assess fetal viability and growth and the amount of amniotic fluid. We did not follow up patients in group 2 because of the association of structural defects of the fetus with a poor outcome of pregnancy.

\section{Results}

In group 1 chorionic tissue was obtained at the first attempt in 90 of the 106 patients (85\%) and at the second attempt during the same session in a further 15 patients; in one patient enough material could not be obtained for cytogenetic analysis. In group 2 the first attempt was successful in 19 of the 21 patients $(90 \%)$, and the second attempt was successful in the remaining two. Between $10 \mathrm{mg}$ and $50 \mathrm{mg}$ (median $20 \mathrm{mg}$ ) of chorionic tissue was collected in group 1 and between $10 \mathrm{mg}$ and $60 \mathrm{mg}$ (median $25 \mathrm{mg}$ ) in group 2 . In both groups the position of the placenta (anterior in 66; posterior in 61) did not affect the number of attempts at sampling or the amount of chorionic tissue obtained. Karyotyping was unsuccessful in two cases in both groups (gestational age $17,18,29$, and 38 weeks and amount of chorionic tissue aspirated $10,15,20$, and $30 \mathrm{mg}$ ). In the remaining cases the karyotype was available within 48 hours after sampling.

In group 1 six abnormal karyotypes were detected, all of which occurred in older mothers; table II shows details of the karyotypes. In one patient (case 1) a

TABLE II-Nature of abnormal karyotypes in patients of advanced maternal age in group 1

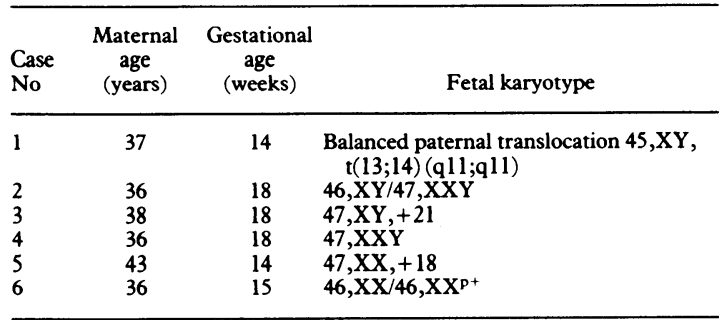

balanced paternal translocation was found and the pregnancy was allowed to continue. In the five remaining cases the pregnancy was terminated. Cultures of fibroblast from the fetuses confirmed abnormal karyotypes in four cases and absence of the $\mathrm{X}^{\mathrm{p}}$ chromosome in one (case 6). Follow up of 101 patients from group 1 at four weeks after sampling showed one fetal death at 18 weeks of gestation in a 38 year old mother who had no history of leakage of amniotic fluid. Postmortem examination showed noabnormalities. In the remaining 100 patients the pregnancy had progressed uneventfully. On ultrasonography the fetuses were alive and their growth was normal; the amount of amniotic fluid was normal in all cases. At the time of writing 25 infants had been delivered at term with birth weights between the 10th and 90th centiles for weeks of gestation, according to the tables of Kloosterman ${ }^{8}$ corrected for maternal parity and fetal sex. Congenital abnormalities and discrepancies of sex were not seen. One case of severe intrauterine growth retardation was diagnosed 12 weeks after sampling in a 43 year old woman who was gravida II, para 1. Caesarean section was performed at 29 weeks because of fetal distress, and a female infant weighing $680 \mathrm{~g}$ was delivered, who died two days later of severe respiratory distress.
In group 2 we detected only one abnormal karyotype $(45, \mathrm{X})$, at 16 weeks of gestation; the fetus had hygroma colli. The pregnancy was terminated and the diagnosis confirmed by culturing fetal fibroblasts. Of the remaining 20 pregnancies, five were terminated because of the severity of the structural defects of the fetus and 15 continued. The 15 that continued resulted in three intrauterine deaths, four neonatal deaths, and eight children who were alive at 1 month.

\section{Discussion}

Chorionic tissue was collected at the first attempt in 109 of the 127 patients and at the second attempt in a further 17 independent of the position of the placenta. Karyotyping was successful in 121 of all 126 cases. More than $30 \mathrm{mg}$ of chorionic tissue was obtained in 47 patients, which was sufficient to permit direct biochemical analysis and analysis of DNA. The number of successful samplings and the amount of aspirated chorionic tissue did not differ between the groups. In group 2 mitoses were not observed in two out of five patients in whom sampling was done beyond 28 weeks of gestation. In the three remaining patients the karyotype was assessed numerically, although the presence of minor structural chromosomal defects may have been overlooked. These findings show that late chorionic villus sampling is a reliable procedure during the second trimester, whereas thereafter problems may arise because of the number and quality of mitoses.

The safety of the sampling technique was determined in group 1 by ultrasonography four weeks after the procedure. Apart from one unexplained fetal death signs of adverse fetal development were not seen. The one case of intrauterine growth retardation with progressive fetal hypoxia, which was diagnosed at 29 weeks of gestation, was not considered to be related to the sampling procedure because of the long term interval after sampling and because the condition had occurred in the previous pregnancy. Another method for rapid karyotyping in late pregnancy is cordocentesis ${ }^{90}$; this technique seems to be safe, though lymphocytes must be cultured to obtain the karyotype, which usually takes four days. Whereas transabdominal chorionic villus sampling may be easier to perform, particularly during the early second trimester, cordocentesis may be preferred during the third trimester because of problems of the fewer mitoses observed in the chorionic tissue.

In conclusion, late chorionic villus sampling seems to be safe and can be considered to be a valuable additional technique in detecting fetal diseases, particularly in the second trimester.

We are grateful to the Stichting Klinische Genetica, Rotterdam, for its financial support.

1 Brambati B, Oldrini A, Ferrazzi E, Lanzani A. Chorionic villus sampling: an analysis of the obstetric experience of 1000 cases. Prenat Diagn 1987;7 157-69.

2 Smidt-Jensen S, Hahnemann N. Transabdominal fine needle biopsy from chorionic villi in the first trimester. Prenat Diagn 1984;4:163-9.

3 Nicolaides KH, Rodeck CH, Soothill PW, Warren RC. Why confine chorioni villus (placental) biopsy to the first trimester? Lancet 1986;i:543-4

4 Szabo J, Gellen J, Szemere G. Mid-trimester chorionic biopsy. Br $\mathcal{O}$ Obstet Gynaecol 1986;93:512-3.

5 Holzgreve W, Miny P, Basaran S, Fuhrmann W, Belle FK. Safety of placental biopsy in the second and third trimesters. N Engl F Med 1987;317:1159.

6 Simoni G, Brambati B, Danesino C. Efficient direct chromosome analyses and enzyme determinations from chorionic villi samples in the first trimester of pregnancy. Hum Genet 1983;63:349-57.

7 Gibas LM, Grujic S, Barr MA, Jackson LG. A simple technique for obtaining high quality chromosome preparations from chorionic villus samples using high quality chromosome preparations from chor

8 Kloosterman G. On intrauterine growth. The significance of prenatal care. Kloosterman G. On intrauterine growth.

9 Daffos F, Capella-Pavlovsky M, Forestier F. Fetal blood sampling during pregnancy with the use of a needle guided by ultrasound: a study of 606 consecutive cases. Am f Obstet Gynecol 1985;153:655-60.

10 Nicolaides $\mathrm{KH}$, Rodeck $\mathrm{CH}$, Gosden CM. Rapid karyotyping in non-lethal fetal malformations. Lancet 1986;i:283-6.

(Accepted 20 May 1988) 